\title{
The High Frequency (HF) Ultrasound as a Useful Imaging Technique for the Efficacy Assessment of Different Anti-Cellulite Treatments
}

\author{
Mlosek Robert Krzysztof ${ }^{1^{*}}$, Malinowska Sylwia ${ }^{2}$, Dębowska Renata ${ }^{3}$, Lewandowski Marcin ${ }^{4}$, \\ Nowicki Andrzej ${ }^{4}$ \\ ${ }^{1}$ Department of Diagnostic Imaging, II Medical Faculty, Medical University of Warsaw, Warsaw, Poland; ${ }^{2}$ Life-Beauty, Grodzisk \\ Mazowiecki, Poland; ${ }^{3}$ Dr. Irena Eris Scientific Research Center, Warsaw, Poland; ${ }^{4}$ Institute of Fundamental Technological Research \\ of the Polish Academy of Sciences in Warsaw, Warsaw, Poland. \\ Email: ${ }^{*}$ mpage@wp.pl
}

Received November $13^{\text {th }}, 2012$; revised December $15^{\text {th }}, 2012$; accepted December $24^{\text {th }}, 2012$

\begin{abstract}
The purpose of the research was to evaluate the role of high frequency ultrasound in monitoring and efficacy assessment of anti-cellulite treatments. A group of 66 women used 3 different types of anti-cellulite treatments; additionally a placebo group $(\mathrm{n}=18)$ was created. The $\mu$-Scan ultrasound device with a $35 \mathrm{MHz}$ mechanical probe was used for the examinations. The following parameters were subjected to the ultrasound evaluation: epidermis thickness, dermis thickness, dermis echogenicity, the length and area of subcutaneous tissue bands projecting into the dermis (dermis-hypodermis junction), as well as the presence/absence of edema within the dermis. As a result of anti-cellulite treatment, the length and area of dermis-hypodermis junction significantly decreased, and dermis echogenicity significantly increased. Ultrasound imaging made it possible to evaluate the efficacy of the applied treatments. The high frequency ultrasound is a useful imaging technique for the application in aesthetic dermatology and cosmetology.
\end{abstract}

Keywords: Aesthetic Medicine; Cellulite; Anti-Cellulite Treatment; High Frequency Ultrasound; Skin Ultrasound

\section{Introduction}

Owing to the offered advantages, ultrasound imaging has become the most popular and commonly used technique in contemporary medicine. The advances in new technologies are reflected by the dynamic development of ultrasound scanning. Therefore this imaging technique may be applied for the evaluation of new areas of the human body. In compliance with the abovementioned, the development of HF ultrasound probes made it possible to apply ultrasound imaging in ophthalmology and dermatology. Harnold and Miller, who first examined the skin using the $15 \mathrm{MHz}$ ultrasound probes, are considered to be the pioneers in skin ultrasound scanning [1]. Yano's team developed one of the first skin ultrasound machines in 1980's [2]. Aesthetic medicine and cosmetology are the two areas, which may particularly benefit from the use of ultrasound scanning. They both develop dynamically, however, they lack the methods to enable the objective monitoring and efficacy assessment of the performed procedures or administered treatments. The use of HF skin ultrasonography is then perceived as an op-

"Corresponding author. portunity. One of the key problems in aesthetic medicine is connective tissue fibrosis involving mainly the thighs, abdomen and buttocks [3-6] which is referred to as cellulite. It affects approximately $85 \%$ - $90 \%$ of female population and increasingly affects the male population, as well [7]. Until present, the stage of cellulite development has been usually assessed using palpation (and specifically developed scales), macrophotography or termography $[4,8-10]$. The magnetic resonance imaging (MRI), computed tomography (CT) and ultrasound scanning were also tried $[6,11,12]$. However, due to economic reasons and accessibility, it is only the ultrasound scanning which can become more widespread.

The purpose of present research was to evaluate the utility and applicability of HF ultrasound in skin imaging, based on the example of anti-cellulite treatments.

\section{Material and Methods}

The described research was conducted between 2008 and 2011. 84 women were enrolled, aged 22 to 61 years (the medium age was 42.04 y.o.). After enrollment, the women were randomized into smaller subgroups, which were ad- 
ministered different anti-cellulite treatments. Different types of cellulite-reducing treatments were selected deliberately, in order to investigate whether the ultrasound changes observed in cellulite patients are of the same nature, regardless of the applied treatment, or they are specific for a given treatment only. All women used anti-cellulite treatmend based on Pharmaceris C dermocosmetics (manufactured by Dr. Irena Eris Cosmetic Laboratories). Group $1\left(\mathrm{n}_{1}=22\right)$ rubbed the anti-cellulite cream into the involved skin areas. The cream was applied twice a day for 30 days. Group $2\left(\mathrm{n}_{2}=20\right)$ was administered the oral dietary supplement for 30 days. Group $3\left(n_{3}=24\right)$ used both the anti-cellulite cream and dietary supplement for 30 days. Group $4\left(\mathrm{n}_{4}=18\right)$ received placebo treatment.

The diagnosis of cellulite was made by palpation in all subjects prior to enrolment. During the palpation, the stage of cellulite development was assessed using the Nürnberger-Müller scale and the thigh circumference was measured at the area to be scanned using the HF ultrasound. Additionally, skin moisturization, the degree of folding of the skin (surface- $\mathrm{S}$ parameter), volume and depth of skin folding (volume-V parameter), were evaluated. Volume - it calculates the amount of liquid needed in the calculation area to fill the image until the average height of all mountains. The smoother area before filling up, the less liquid is needed. The result is expressed in $\mathrm{V} / \mathrm{mm}^{2}$ (one-dimensional in gray values). Surface-this graph shows the size of the "folding" surface in comparison with the stretched "ironed" surface. The smoother the area was before stretching, the closer the two values are together. The result is expressed in \%. All the measurements were taken in the same area, using the assumed methodology and the following devices: Corneometeru CM 825 and Video Digitizer VD 300 (Courage-Khazaka Electronic GmbH, Köln, Germany).

Ultrasound skin scanning was performed twice in each woman: prior to treatment commencement (at baseline), and after its completion. The posterior thigh skin was scanned, always in the same area. The HF ultrasound machine was used for the evaluation, which is the $\mu$-Scan developed by the team of professor Nowicki (Institute of Fundamental Technological Research, Polish Academy of Sciences, Warsaw, Poland). The system consists of a $\mu$-Scan module, a portable PC computer and a scanning head (Figure 1). The unit is equipped with the new type of thick film, high-frequency transducers $(20-35 \mathrm{MHz})$ and enables imaging the area $7 \times 7 \mathrm{~mm}$ of the tissue with the resolution of $50 \mu \mathrm{m}$. In order to determine the lateral resolution of the scanning beam, the transducer was mounted in the Scanning Acoustic Microscope (SAM) head, so that the transducer was operating in transmittingreceiving mode using the SAM electronics. The field

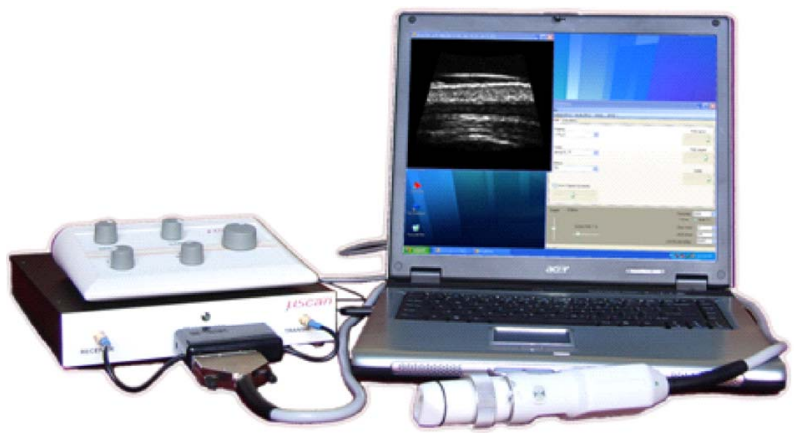

Figure 1. $\mu$-Scan system used for cellulite investigation.

emitted by the transducer was probed with a small spherical reflector (100 $\mu \mathrm{m}$ diameter). This reflector was scanned point by point in the transducers field at the constant distance from the transducer. The pulses reflected from a ball-like reflector were next captured by the transducer and sent to the SAM receiver. The amplitude of echoes was used for the control of brightness of the pixels on SAM's monitor. After the scan was done, the image corresponding to pressure field distribution was created and stored. The measurements were taken in the focal plane. The scanning area was $0.4 \mathrm{~mm} \times 0.4 \mathrm{~mm}$. The image obtained in focus $(11 \mathrm{~mm})$ shows perfect focusing properties of the transducer (Figure 2). The thick film transducer working at $33 \mathrm{MHz}$ center frequency exhibits an excellent bandwidth of $84 \%$ thus generating very short pulses (Figure 3). The device features coded transmission resulting in extended penetration depth and high image quality even for higher ultrasound frequencies. The software/hardware enables switching between the different excitation schemes offering the unique possibility to optimize transmitted signal to a given application in the real-time. Portability, low-power consumption and low-cost were obtained by the application of the newest semiconductor technology and full software RF signal processing. The main applications include: dermatology, ophthalmology and cosmetics [13].

The following parameters were subjected to the ultrasound evaluation: epidermis thickness, dermis thickness, dermis echogenicity, the length and area of subcutaneous tissue bands projecting into the dermis (dermis-hypodermis junction), as well as the presence/absence of edema within the dermis.

All women participating in the research had been informed about the type of study they were taking part in, and they had given their informed consent to participate. Preparations used in the study were before the start of this study placed on the market within the European Union (they have all the necessary examinations and certificates required for cosmetics) and conducted therapy was not modified in relation to manufacturer orders. This 


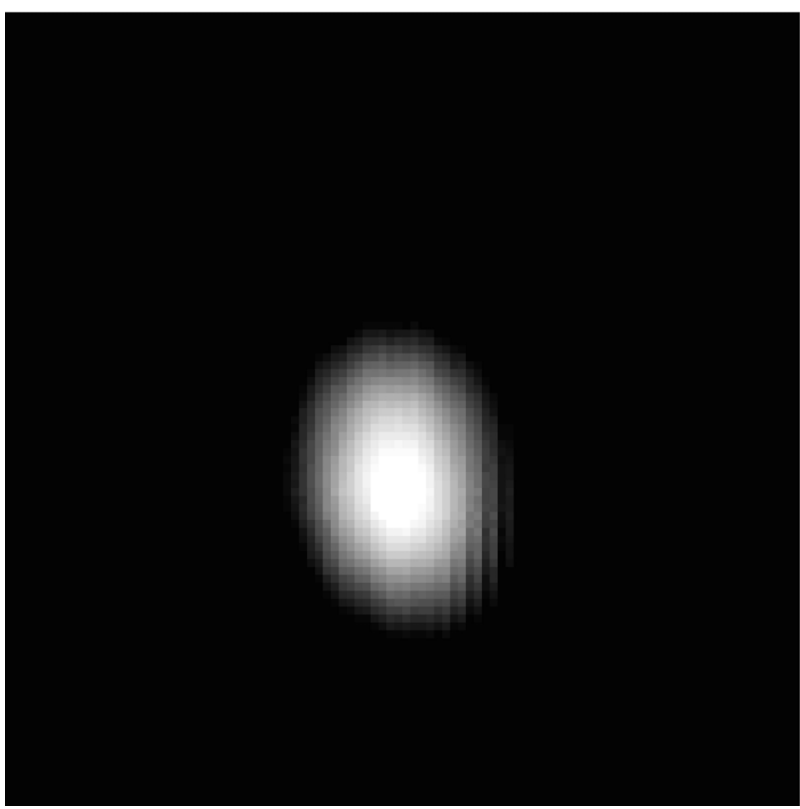

Figure 2. Cross-section of the beam width in the focus plane, $8 \mathrm{~mm}$ from the transducer face. Image size- $0.4 \mathrm{~mm} \times 0.4$ mm.

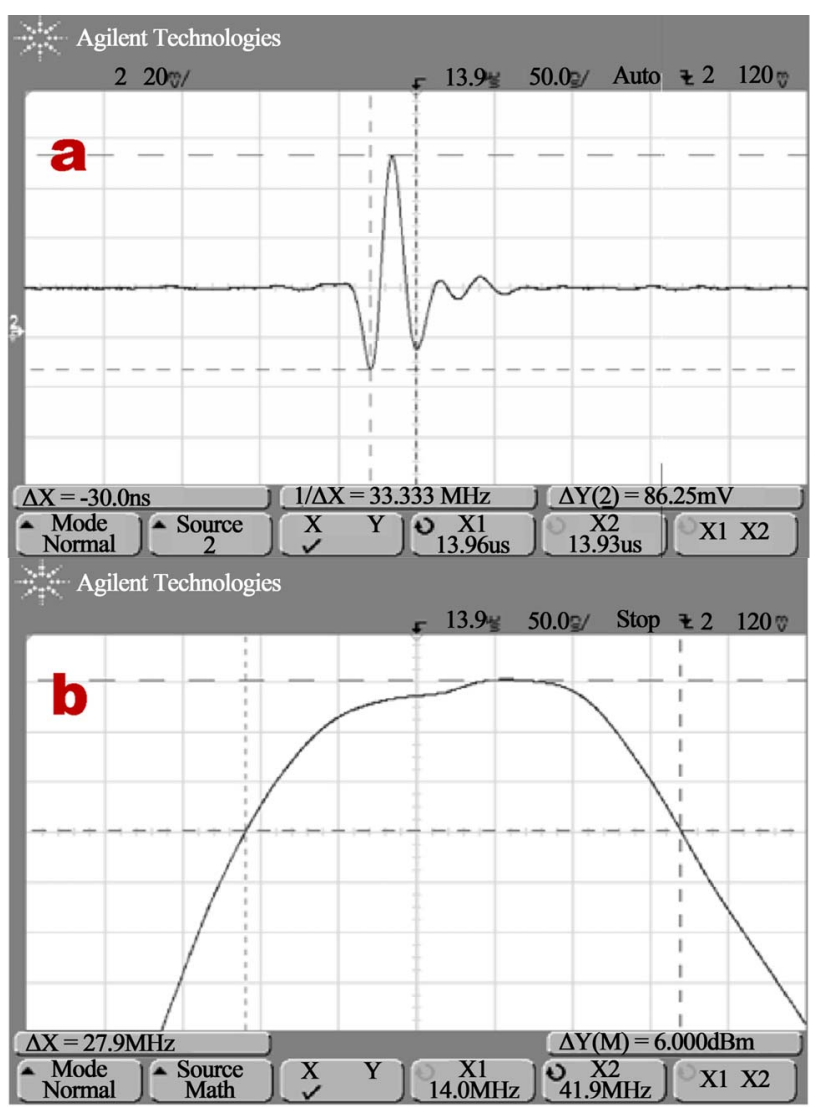

Figure 3. The pulse shape and bandwidth of the thick film transducer. Impulse reflected from the perfect reflector, center frequency $=33 \mathrm{MHz}$ (a) and transducer bandwidth = $28 \mathrm{MHz}(84 \%$ fractional bandwidth) (b). research did not require the consent of the Ethics Committee.

\section{Statistical Analysis}

The statistical analysis was performed using Statistica 8 software. In order to determine the sample distribution, the W Shapiro-Wilk test was used. The parametric Student's T-test and non-parametric Wilcoxon signed-rank test were used. Additionally, the one-way analysis of variance (ANOVA) and Kruskal-Wallis one-way analysis of variance were performed. The $\alpha=0.05$ was considered statistically significant.

\section{Results}

The collected data was analysed in two ways. First of all, the data was compared between the baseline and treatment completion stage for the subjects using different anti-cellulite therapies (the data in groups 1 - 3 was analysed collectively), and in placebo group (Table 1). Then, the detailed comparisons were made between the results for each individual parameter within each group using a specific anti-cellulite treatment (Table 2).

Statistical analysis showed significant improvements in all the assessed parameters in the group of subjects using anti-cellulite treatments (groups 1 - 3 collectively). Among the ultrasound-assessed parameters, the largest improvement was observed in the length and area of dermis-hypodermis junction (Table 1). After treatment completion, the subcutaneous tissue bands were shortened by $0.35 \mathrm{~mm}$, which means their reduction by $42.17 \%$ (Figure 4). Similar improvement was observed in the area of dermis-hypodermis junction (Table 1). In the enrolled women, after treatment completion, this area was reduced on the average by $0.37 \mathrm{~mm}^{2}$, which means an improvement of $45.12 \%$ (Figure 5). The area dermis-hypodermis interface did not improved significantly in the placebo group. However, the statistically significant shortening of subcutaneous tissue bands was observed in the placebo group. According to the measurement data, the bands were shortened by $0.05 \mathrm{~mm}$. As it is only $6.1 \%$, the difference can be suspected to be due to the measurement error. Additionally, the analysis of results for the individual groups using different types of anti-cellulite treatment confirmed, that after the treatment completion both the area and length of bands projecting into the subcutaneous tissue decreased. No statistically significant differences were observed between the groups using various types of anti-cellulite treatment (Table 2). After treatment completion, the ultrasound scan showed also the reduced thickness of epidermis and dermis (Table 1). The thinning of dermis by $0.27 \mathrm{~mm}$ (16.07\%), and epidermis by $0.02 \mathrm{~mm}(12.50 \%)$ was observed (Fig- 
Table 1. The results in groups which used anti-cellulite therapy and in placebo group.

\begin{tabular}{|c|c|c|c|c|c|c|c|c|c|c|c|}
\hline & \multirow[b]{2}{*}{ Parametres } & \multicolumn{5}{|c|}{ Anti-cellulite therapy $n=66$} & \multicolumn{5}{|c|}{ Placebo $\mathrm{n}=18$} \\
\hline & & $\begin{array}{c}\bar{x} \\
\text { before } \\
\text { therapy } \\
{[\mathrm{mm}]}\end{array}$ & $\begin{array}{c}\bar{x} \\
\text { after } \\
\text { therapy } \\
{[\mathrm{mm}]}\end{array}$ & $\begin{array}{l}\text { t-Studenta } \\
(\mathrm{t}) / \\
\text { Wilcoxons' } \\
\text { test }(\mathrm{Z})\end{array}$ & $\mathrm{p}$ & $\begin{array}{c}\text { Change in } \\
\%\end{array}$ & $\begin{array}{c}\bar{x} \\
\text { before } \\
\text { therapy } \\
{[\mathrm{mm}]}\end{array}$ & $\begin{array}{c}\bar{x} \\
\text { after } \\
\text { therapy } \\
{[\mathrm{mm}]}\end{array}$ & $\begin{array}{c}\text { t-Studenta } \\
(\mathrm{t}) / \\
\text { Wilcoxons } \\
\text { test }(\mathrm{T})\end{array}$ & $\mathrm{p}$ & $\begin{array}{c}\text { Change in } \\
\%\end{array}$ \\
\hline \multirow{6}{*}{ 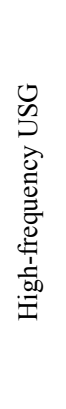 } & Thickness of epidermis & 0.16 & 0.14 & $Z=4.06$ & $\leq 0.001$ & $-12.50 \%$ & 0.16 & 0.16 & $\mathrm{~T}=10.5$ & 0.294 & $0 \%$ \\
\hline & Thickness of dermis & 1.68 & 1.41 & $\mathrm{t}=8.57$ & $\leq 0.001$ & $-16.07 \%$ & 1.69 & 1.73 & $\mathrm{t}=-1.98$ & 0.064 & $+2.37 \%$ \\
\hline & Echogenicity & 17380.23 & 18071.56 & $Z=6.35$ & $\leq 0.001$ & $3.98 \%$ & 16930.22 & 16934.39 & $\mathrm{t}=70$ & 0.758 & $-0.03 \%$ \\
\hline & $\begin{array}{l}\text { Length of a subcutaneous } \\
\text { tissue bands }\end{array}$ & 0.83 & 0.48 & $Z=6.32$ & $\leq 0.001$ & $-42.17 \%$ & 0.82 & 0.77 & $\mathrm{t}=2.48$ & 0.024 & $-6.1 \%$ \\
\hline & $\begin{array}{l}\text { Area of a subcutaneous } \\
\text { tissue bands }\end{array}$ & 0.82 & 0.45 & $Z=6.46$ & $\leq 0.001$ & $-45.12 \%$ & 0.70 & 0.68 & $t=1.63$ & 0.122 & $-2.86 \%$ \\
\hline & $\begin{array}{c}\text { Presence/absence of } \\
\text { edemas }\end{array}$ & 0.77 & 0.55 & $Z=2.74$ & 0.006 & $-28.57 \%$ & 0.78 & 0.72 & $\mathrm{t}=1.00$ & 0.331 & $-7.69 \%$ \\
\hline \multirow{2}{*}{ 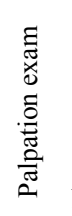 } & $\begin{array}{l}\text { Thigh circumference at } \\
\text { the place of US } \\
\text { examination }\end{array}$ & 56.89 & 54.81 & $Z=6.85$ & $\leq 0.001$ & $-3.66 \%$ & 57.69 & 57.36 & $\mathrm{t}=2.06$ & 0.055 & $-0.57 \%$ \\
\hline & $\begin{array}{c}\text { Stage of cellulite } \\
\text { according to } \\
\text { Nürnberger-Müller scale }\end{array}$ & 2.89 & 1.36 & $Z=6.45$ & $\leq 0.001$ & $-52.94 \%$ & 2.56 & 2.33 & $\mathrm{~T}=0$ & 0.068 & $-8.98 \%$ \\
\hline \multirow{3}{*}{ 吾 } & Skin moisturization & 32.71 & 37.90 & $\mathrm{t}=-4.85$ & $\leq 0.001$ & $15.87 \%$ & 40.61 & 42.89 & $\mathrm{t}=-1.89$ & 0.076 & $+5.61 \%$ \\
\hline & S (surface) & 3.74 & 3.45 & $\mathrm{Z}=2.29$ & 0.022 & $-7.75 \%$ & 3.53 & 3.44 & $\mathrm{~T}=84$ & 0.948 & $-2.55 \%$ \\
\hline & V (volume) & 65.06 & 46.57 & $Z=4.81$ & $\leq 0.001$ & $-28.42 \%$ & 49.33 & 39.44 & $\mathrm{~T}=35.5$ & 0.029 & $-20.04 \%$ \\
\hline
\end{tabular}

Legends: $\mathrm{n}$ - number of women in test, $\bar{x}$ arithmetic mean, $\mathrm{t}-$ value of the $\mathrm{t}$ - Student test, $\mathrm{T} / \mathrm{Z}-$ value of the Wilcoxon Test $(\mathrm{T}-$ in trial $<25, \mathrm{Z}-$ in trial $>$ 25), $\mathrm{p}$ — statistically significantly level for the Wilcoxon Test or $\mathrm{t}$-Student test.

ure 6). The result analysis for each sample showed that the statistically significant reduction of epidermis thickness occurred in the group using the anti-cellulite cream and cream + oral dietary supplement strategy. No statistically significant reduction was observed in the group using the oral dietary supplement only (Table 2) and in the placebo group (Table 1). In terms of dermis thickness, in all samples, which received some anti-cellulite treatment, statistically significant improvement was observed (Table 2). In the group receiving the combination of the anti-cellulite cream and oral dietary supplement, the dermis thickness was reduced by approximately $20 \%$ compared to $8.98 \%$ in the group using the dietary supplement only. No statistically significant differences were observed in the placebo group (Table 1). After treatment completion, the number of women in whom ultrasound scan revealed the edema within the dermis, decreased by 28.57\% (Table 1, Figure 7). No statistically significant edema improvement was observed in the placebo group. Analyzing the data separately for each group (Table 2) we observed that the largest improvement occurred in women using the anti-cellulite cream $(67.07 \%)$. Also dermis echogenicity displayed statistically significant improvement (Figure 8). Statistically significant differ- ences were observed both in the collective analysis for the groups 1 - 3 (Table 1), and in separate analysis of results within each individual group (Table 2). The largest improvement was observed in the sample using the anti-cellulite cream. There were no statistically significant improvements in the placebo group.

In terms of the parameters evaluated during palpation, i.e. thigh circumference and stage of cellulite development, the statistically significant differences were observed in all women using some anti-cellulite treatment (groups 1 - 3 collectively). The thigh circumference was reduced by $3.66 \%$ (Table 1). Also the stage of cellulite development assessed using the Nürnberger-Müller scale was reduced and the difference was 52.94\% (Table 1). The analysis of results separately for each group confirmed the abovementioned observations, however the largest improvement in this respect was observed in the group using both the anti-cellulite cream and oral dietary supplement (Table 2). Neither the thigh circumference nor the cellulite stage changed significantly in placebo group (Table 1).

In terms of the parameters evaluated using the measurement devices, the statistically significant improvement of all the parameters (Table 1) was observed in all 
Table 2. Comparison of results in 3 groups before and after anti-cellulite therapy.

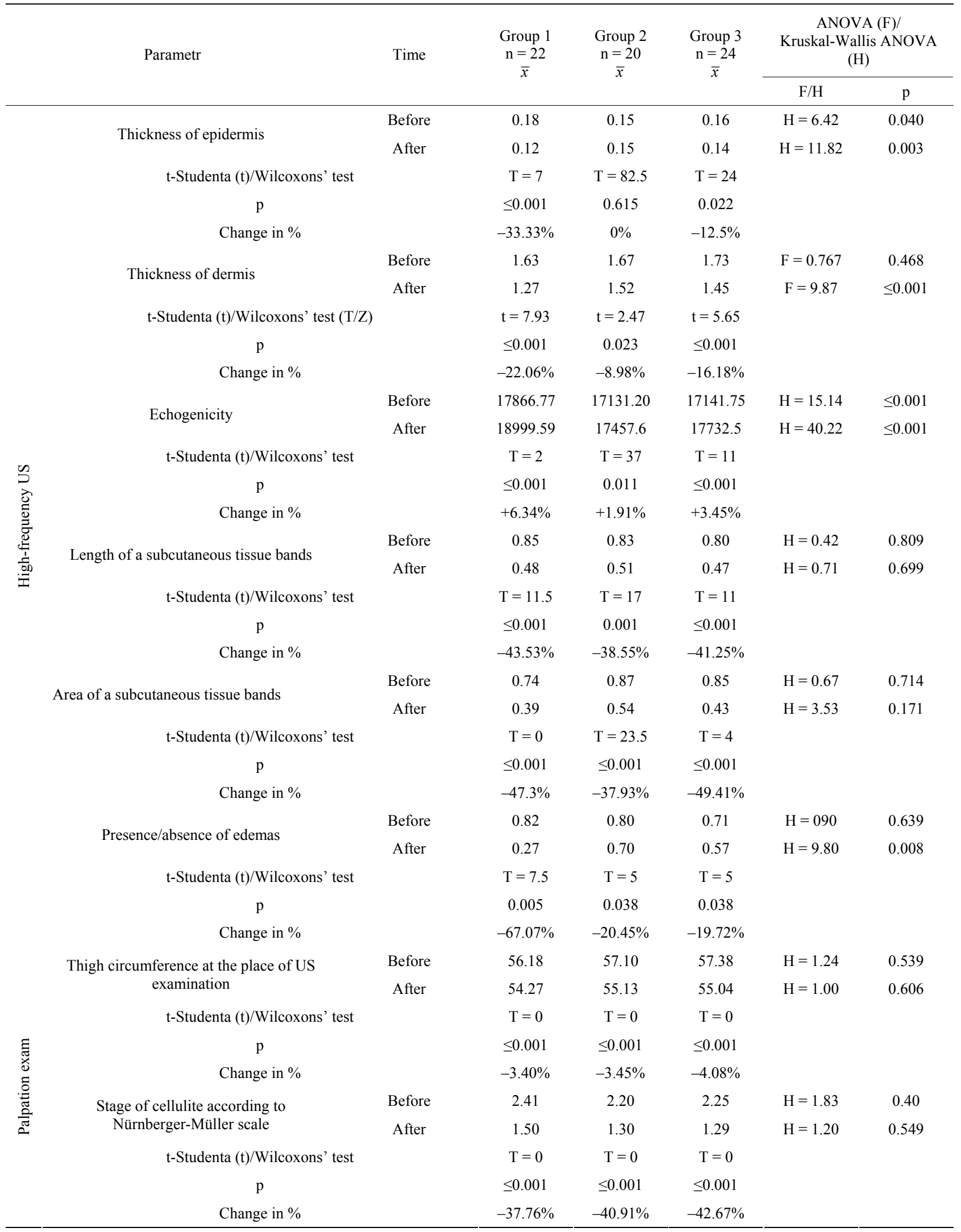




\section{Continued}

\begin{tabular}{|c|c|c|c|c|c|c|c|}
\hline \multirow{15}{*}{ 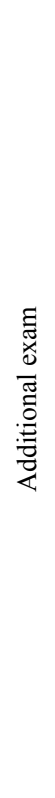 } & \multirow{2}{*}{ Skin moisturization } & Before & 35.73 & 31.15 & 31.25 & $\mathrm{~F}=3.17$ & 0.49 \\
\hline & & After & 41.75 & 32.40 & 38.96 & $\mathrm{~F}=8.37$ & $\leq 0.001$ \\
\hline & t-Studenta (t)/Wilcoxons' test & & $\mathrm{t}=3.08$ & $\mathrm{t}=-0.554$ & $t=-6.73$ & & \\
\hline & $\mathrm{p}$ & & 0.006 & 0.585 & $\leq 0.001$ & & \\
\hline & Change in $\%$ & & $+16.85 \%$ & $+4.01 \%$ & $+24.67 \%$ & & \\
\hline & \multirow{2}{*}{ S (surface) } & Before & 3.58 & 3.72 & 3.91 & $\mathrm{H}=1.52$ & 0.467 \\
\hline & & After & 3.39 & 4.10 & 3.05 & $H=15.73$ & $\leq 0.001$ \\
\hline & \multicolumn{2}{|l|}{ t-Studenta (t)/Wilcoxons' test } & $\mathrm{t}=1.07$ & $\mathrm{~T}=49$ & $\mathrm{t}=5.524$ & & \\
\hline & \multicolumn{2}{|l|}{$\mathrm{p}$} & 0.296 & 0.193 & $\leq 0.001$ & & \\
\hline & \multicolumn{2}{|l|}{ Change in $\%$} & $-5.31 \%$ & $+10.22 \%$ & $-21.99 \%$ & & \\
\hline & \multirow{2}{*}{$\mathrm{V}$ (volume) } & Przed terapią & 60.50 & 66.65 & 68.13 & $\mathrm{H}=1.95$ & 0.378 \\
\hline & & Po terapii & 44.64 & 56.24 & 41.50 & $\mathrm{H}=3.56$ & 0.169 \\
\hline & \multicolumn{2}{|l|}{ t-Studenta (t)/Wilcoxons' test } & $\mathrm{T}=57$ & $\mathrm{~T}=44.5$ & $\mathrm{t}=5.91$ & & \\
\hline & \multicolumn{2}{|l|}{$\mathrm{p}$} & 0.024 & 0.123 & $\leq 0.001$ & & \\
\hline & \multicolumn{2}{|l|}{ Change in \% } & $-26,22 \%$ & $-15.62 \%$ & $-39.09 \%$ & & \\
\hline
\end{tabular}

Legends: $\mathrm{n}-$ number of women in test, $\bar{x}$ arithmetic mean, $\mathrm{t}-$ value of the $\mathrm{t}-\mathrm{Student}$ test, $\mathrm{T}$-value of the Wilcoxon Test, $\mathrm{F}-\mathrm{value}$ of Anova, $\mathrm{H}-\mathrm{value}$ of Kruskal-Wallis ANOVA, $\mathrm{p}$ — statistically significantly level for the Wilcoxon Test or t—Student test.

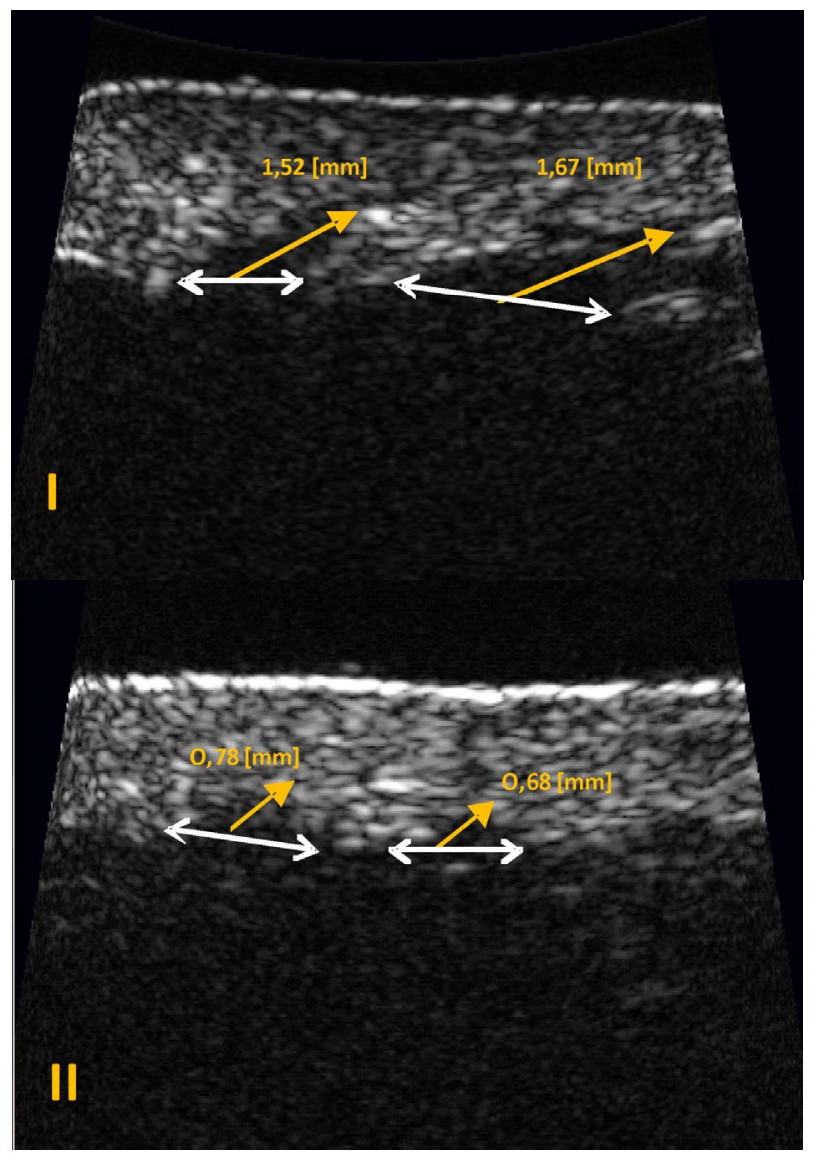

Figure 4. The length of a subcutaneous tissue bands projecting into the dermis: (I) Before; (II) After treatment.

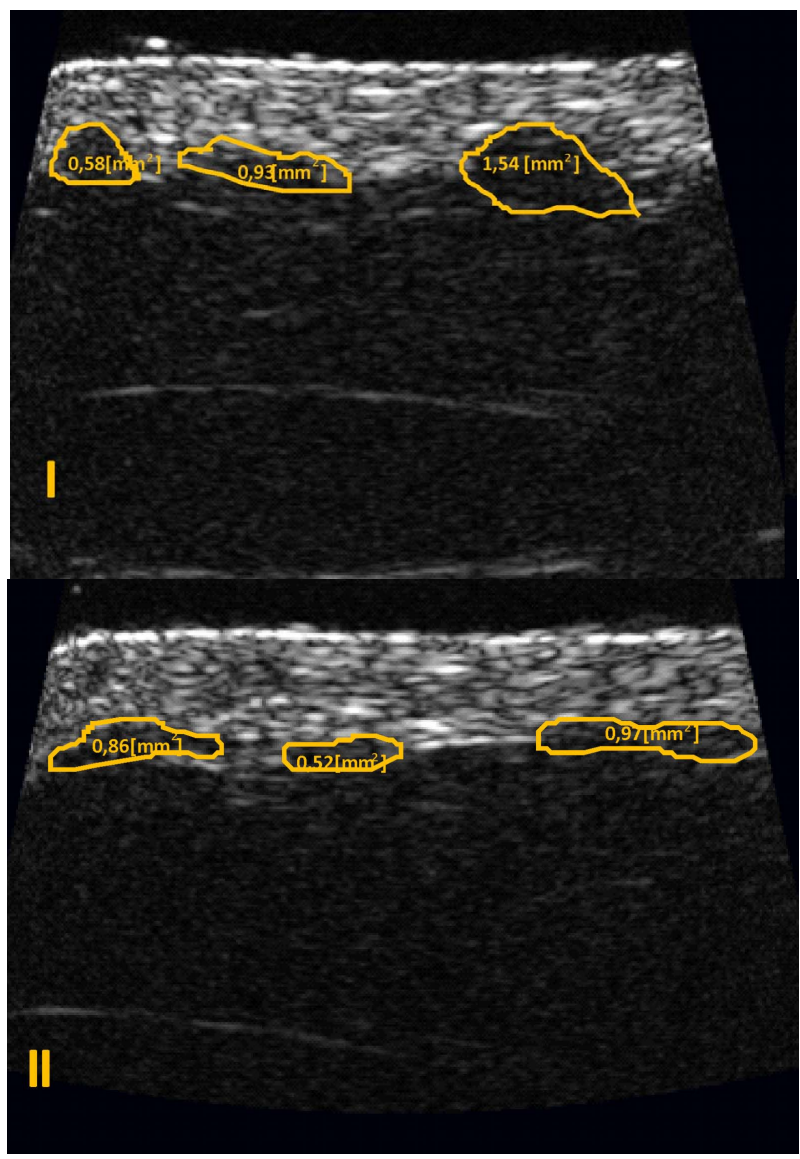

Figure 5. The area of a subcutaneous tissue bands projecting into the dermis: (I) Before, (II) After treatment. 


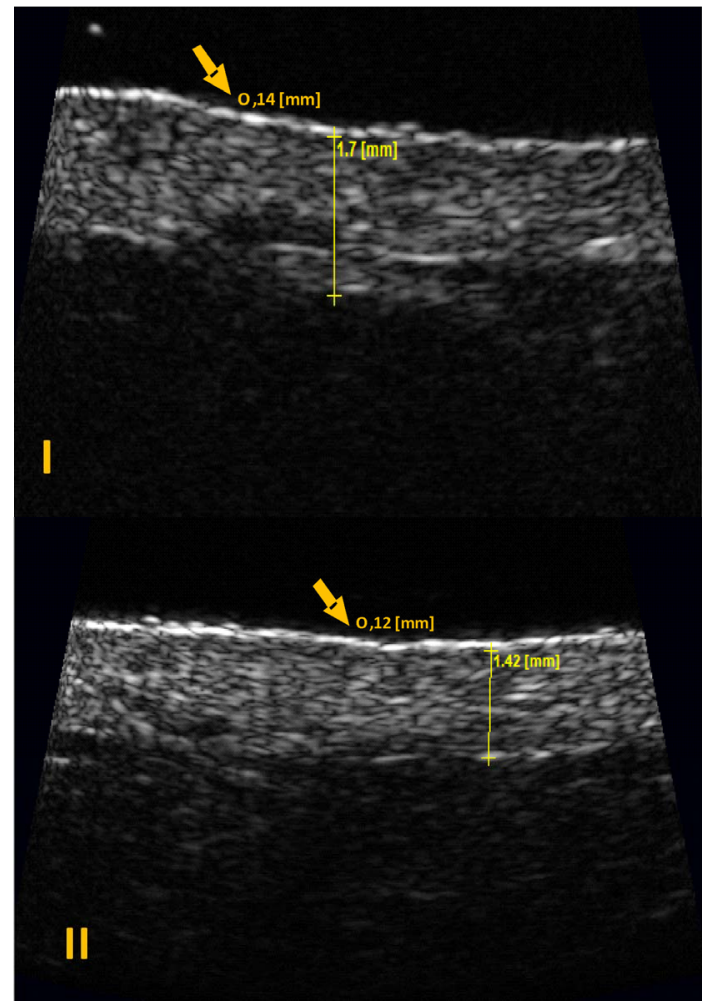

Figure 6. Dermis and epidermis thickness: (I) Before; (II) After treatment.

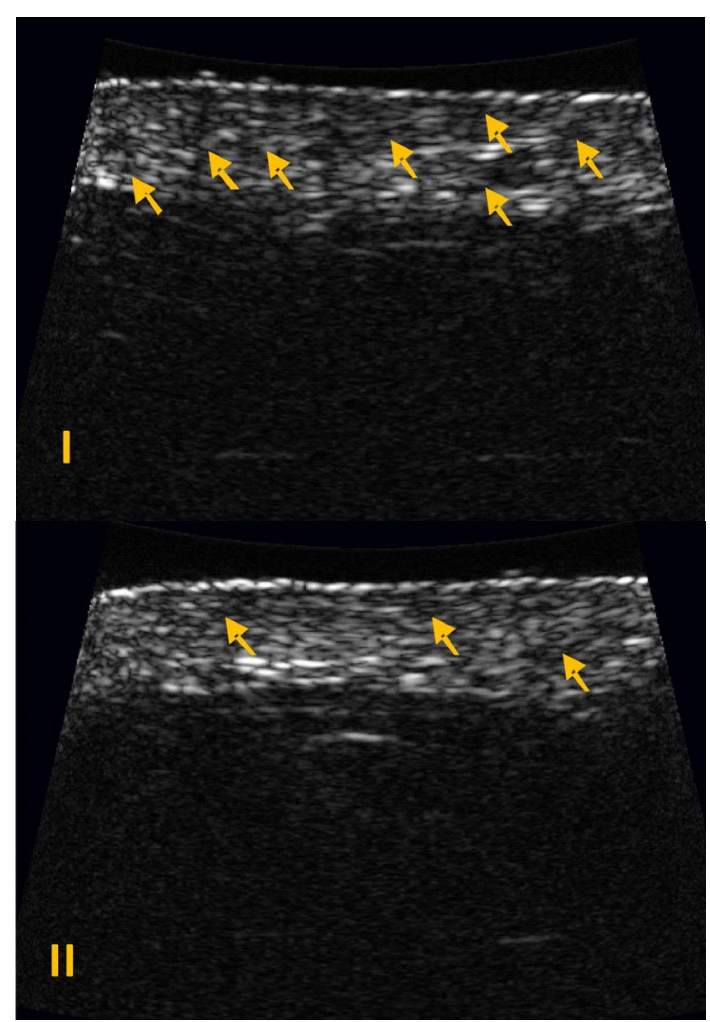

Figure 7. The presence/absence of edemas: (I) Before; (II) After treatment.

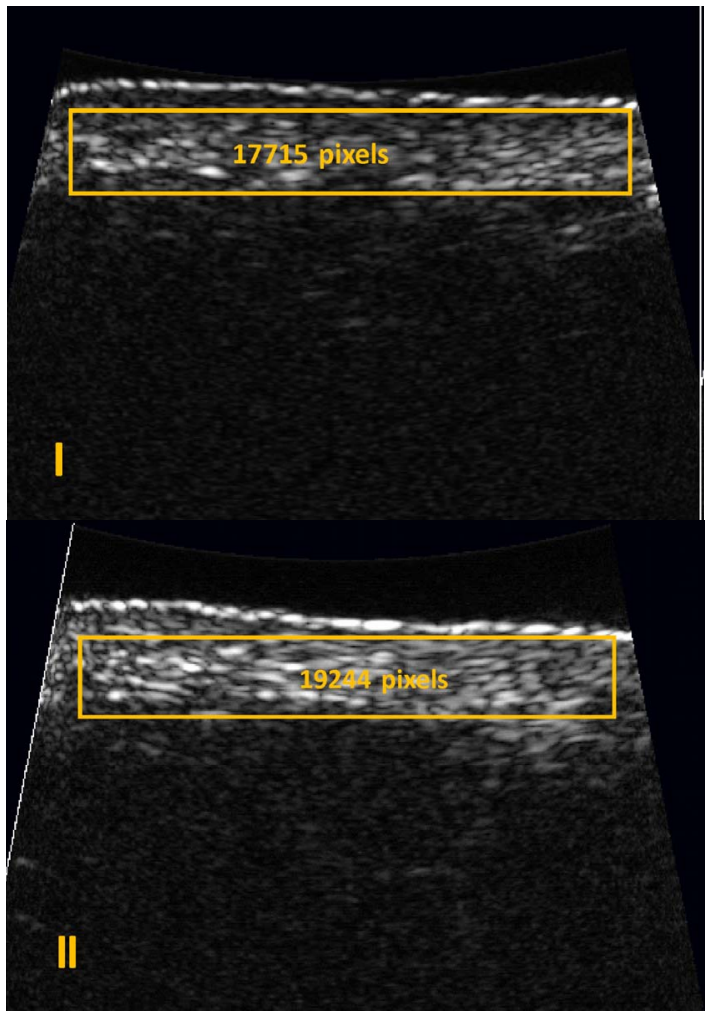

Figure 8. Dermis echogenicity: (I) Before; (II) After treatment.

women using some anti-cellulite treatment (groups 1 - 3 collectively). After treatment completion, skin moisturization increased, whereas the surface (S) and volume (V) of skin folding decreased. The analysis performed individually for each sample showed no statistically significant improvement in the groups using the dietary supplement (Table 2). Also in the group using the anti-cellulite cream, the improvement in the surface of skin folding (S) proved to be statistically insignificant. No statistically significant improvement was observed in the placebo group, except for the volume of skin folding (V). According to the obtained results, the volume of skin folding $(\mathrm{V})$ in the placebo group subjects decreased significantly by $20.04 \%$ (Table 1) after treatment completion.

\section{Discussion}

Aesthetic medicine and cosmetology have been developing dynamically in recent years. However, as these are relatively new scientific areas, the reliable research methodology has not been developed yet, which could provide for the objective verification of the administered treatments and performed procedures. The search for the non-invasive methods in order to monitor the treatment progress has been pending $[4,9,12]$. It is particularly im- 
portant to develop a method for the efficacy assessment of the applied treatments. The HF ultrasonography appears to be an objective method, which is likely to become more widespread in cosmetology and aesthetic medicine. Although the studies of skin ultrasonography have been conducted worldwide for several dozen years, no uniform standards for skin ultrasound scanning have been developed yet.

Our own research shows that the HF ultrasonography enables the monitoring of anti-cellulite treatments. The paper also presents the possibility of HF ultrasound application to the efficacy assessment of various therapeutic strategies. Among the assumed parameters, the measurement of the length and area of subcutaneous tissue bands growing into the dermis should be noted. In cellulite, the dermis-hypodermis junction has a characteristic serrated appearance, which was already mentioned by other researchers $[7,12,14]$. The area of these subcutaneous tissue bands is very important. Our experience shows that these bands do not always have this classic serrated appearance (Figures 4 and 5). They can often be short but growing into a relatively large area. That is why false results may be obtained if only the length of the interface is measured. It is much better and easier to determine its area as well. Dermis echogenicity is another useful parameter. After treatment completion, the increased dermis echogenicity was observed, which is related to the rebuilding of the collagen fibres. As these are fibrous structures, they appear hyperechogenic on an ultrasound scan. M. Gniadecka $[15,16]$ conducted the study of skin echogenicity in the past, and other authors $[4,17]$ confirm the increase in the number of collagen fibers within the dermis as a result of anti-cellulite treatment. The administered treatments significantly reduced the edemas within the dermis, which is potentially due to the improvement in microcirculation $[12,14]$. When discussing this parameter, it should be noted that the ultrasound evaluation of edemas within the dermis is not easy and requires an experienced physician to evaluate the scans, as it is relatively simple to mistake the oedema with the small vessel. That is why it is important to assess this parameter based on an ultrasound scanning video, rather than on a static scan. The reduced dermis thickness was another effect of the applied treatment. The obtained results indirectly confirm the observations of other authors, who also noted the reduced circumference of some body parts as a result of anti-cellulite therapy $[4,12,14,18,19]$. The decreased dermis thickness shows a correlation with the significant reduction of thigh circumference after the treatment. The epidermis thickness proved to be the least useful ultrasound parameter from the point of view of cellulite evaluation. The risk of measurement error is very high here, as epidermis is an extremely thin structure. The ob- tained results showed the statistically significant improvement in the groups of subjects who mechanically rubbed the anti-cellulite cream into the skin. No epidermis thickness differences were observed in the group using the oral dietary supplement and in the placebo group. It allows concluding, that the key factor for epidermis thickness is its mechanical exfoliation. Apart from the improvement observed during the ultrasound scanning, skin moisturization increased, whereas the surface (S) and volume (V) of skin folding decreased. Similarly, the thigh circumference was reduced. These parameters confirm the changes observed during the ultrasound evaluation. The significant differences in the discussed parameters are reflected by the improved skin appearance and decreased stage of cellulite development based on Nürnberger-Müller scale. The attempt to assess the efficacy of various anti-cellulite treatments, which was described in present paper, also justifies the application of ultrasound scanning for skin evaluation. According to the obtained results, the least effective treatment was the administration of oral dietary supplement. The use of anti-cellulite cream proved to be the most effective.

Based on the obtained results as well as previous publications, ultrasonography may be considered useful in monitoring of anti-cellulite treatment efficacy. This method can also be applied for the comparative efficacy assesment of various anti-cellulite strategies. Currently it seems reasonable to continue the research on this topic in order to develop homogenous standards for ultrasound skin scanning, owing to which aesthetic medicine and cosmetology would have the dedicated, objective evaluation method.

\section{REFERENCES}

[1] K. Hoffmann, S. Gammal and K. Winkler, "Skin Tumors in High-Frequency Ultrasound," In: P. Altmeyer, S. Gammal and K. Hoffmann, Eds., Ultrasound in Dermatology, 1992, pp. 181-202.

[2] T. Yano, H. Fukuita, S. Ueno and A. Fukumoto, " $40 \mathrm{MHz}$ Ultrasound Diagnostics System for Dermatologic Examination," IEEE 1987 Ultrasonic Symposium Proceeding, 14-16 October 1987, pp. 857-878.

[3] U. Wollina, A. Gildman and U. Berger, "Esthetic and Cosmetic Dermatology," Dermatology and Therapy, Vol. 21, No. 1, 2008, pp. 118-150. doi:10.1111/j.1529-8019.2008.00179.x

[4] J. P. Ortonne, M. Zartarian and M. Verschoore, C. QueilleRoussel and L. Duteil, "Cellulite and Skin Ageing: Is There Any Interaction?" Journal of the European Academy of Dermatology and Venereology, Vol. 22, No. 7, 2008, pp. 827-834. doi:10.1111/j.1468-3083.2007.02570.x

[5] P. T. Pugliese, "The Pathogenesis of Cellulite: A New Concept," Journal of Cosmetic Dermatology, Vol. 6, No. 2, 2007, pp. 140-142. 
doi:10.1111/j.1473-2165.2007.00312.x

[6] B. Querlux, C. Cornillon and O. Jolivet, "Anatomy and Physiology of Subcutaneous Adipose Tissue by in Vivo Magnetic Resonance Imaging and Spectroscopy: Relationships with Sex and Presence of Cellulite," Skin Research and Technology, Vol. 8, No. 2, 2002, pp. 118-124. doi:10.1034/j.1600-0846.2002.00331.x

[7] M. Rosenbaum, V. Prieto, J. Hellmer, M. Boschmann, J. Krueger, R. L. Leibel and A. G. Ship, "An Exploratory Investigation of the Morphology and Biochemistry of Cellulite," Plastic and Reconstructive Surgery, Vol. 101, No. 7, 1998, pp. 1934-1939. doi:10.1097/00006534-199806000-00025

[8] F. Nürnberger and G. Müller, "So Called Cellulite: An Invented Disease," Journal of Dermatologic Surgery \& Oncology, Vol. 4, No. 3, 1978, pp. 221-229.

[9] S. Bielfeldt, P. Buttgereit, M. Brandt, G. Springmann and K. P. Wilhelm, "Non-Invasive Evaluation Techniques to Quantify the Efficacy of Cosmetic Anti-Cellulite Products," Skin Research and Technology, Vol. 14, No. 3, 2008, pp. 336-346. doi:10.1111/j.1600-0846.2008.00300.x

[10] C. Vincent, M. Szubert, R. Dębowska, K. Bazela, I. Eris, L. Różański, M. Stroiński, Z. Jaskólska and A. Duszyńska, "Zastosowanie Termografii w Diagnostyce Cellulite," Dermatology Estetyczna, Vol. 8, No. 2, 2006, pp. 85-89.

[11] D. M. Hexsel, M. Abreu, T. C. Rodrigues, M. Soirefmann, D. Z. do Prado and M. M. Gamboa, "Side-by-Side Comparison of Areas with and without Cellulite Depressions Using Magnetic Resonance Imaging," Dermatologic Surgery, Vol. 35, No. 10, 2009, pp. 1471-1477. doi:10.1111/j.1524-4725.2009.01260.x

[12] R. K. Mlosek, R. Dębowska, M. Lewandowski, S. Malinowska, R. Truszkowski, A. Nowicki and I. Eris, "The Use of High Frequency Ultrasonography in Monitoring Anti-
Cellulite Therapy-Own Experience," Polish Journal of Cosmetology, Vol. 11, No. 4, 2008, pp. 283-294.

[13] M. Lewandowski and A. Nowicki, "High Frequency Coded Imaging System with RF Software Signal Processing," IEEE UFFC, Vol. 55, No. 8, 2008, pp. 1878-1882. doi:10.1109/TUFFC.2008.871

[14] R. Białynicki-Birula, E. Baran and R. Kuliś-Orzechowska, "Efficacy Evaluation of Anti-Cellulite Activity of Cosmetics Containing Mud-Extractions," Dermatologia Estetyczna, Vol. 6, No. 3, 2004, pp. 155-159.

[15] M. Gniadecka and G. B. E. Jamec, "Quantitative Evaluation of Chronological Ageing and Photoageing in Vivo: Studies on Skin Echogenicity and Thickness," British Journal of Dermatology, Vol. 139, 1998, pp. 815-882. doi:10.1046/j.1365-2133.1998.02506.x

[16] M. Gniadecka, "Effects of Ageing on Dermal Echogenicity," Skin Research and Technology, Vol. 7, 2001, pp. 204 207. doi:10.1034/i.1600-0846.2001.70310.x

[17] C. Lugt, C. Romero, D. Ancona, M. Al-Zarouni, J. Perera and M. A. Trelles, "A Multicenter Study of Cellulite Treatment with a Variable Emission Radio Frequency System," Dermatology and Therapy, Vol. 22, No. 1, 2009, pp. 74-84. doi:10.1111/j.1529-8019.2008.01218.x

[18] W. Manuskiatti, C. Wachirakaphan, N. Lektrakul and S. Varothai, "Circumference Reduction and Cellulite Treatment with a TriPollar Radiofrequency Device: A Pilot Study," Journal of the European Academy of Dermatology and Venereology, Vol. 23, No. 7, 2009, pp. 820-827. doi:10.1111/j.1468-3083.2009.03254.x

[19] S. Boisnic, M. C. Branchet, O. Birnstiel and G. Beilin, "Clinical and Histopathological Study of the TriPollar Home-Use Device for Body Treatments," European Journal of Dermatology, Vol. 20, No. 3, 2010, pp. 367-372. 